\title{
An investigation into failure of Internet firms: Towards development of a conceptual model
}

\author{
Jiwat Ram \\ Shandong University \\ jiwat.ram@gmail.com
}

\section{Zeyang Zhang}

Xi'an Jiaotong - Liverpool University

\section{Abstract}

The last two decades have witnessed an exponential growth in internet and social media based commerce in China, resulting in a number of foreign Internet firms launching their businesses to capitalize on the market opportunities. Surprisingly though, having been successful globally, these firms were not able to remain competitive in China with majority of them suffering losses from their failed ventures and ceasing their operations. Despite this ongoing problem, little or no research exists that might explain what is causing these problems. Addressing this gap in knowledge, we build literature-based insights and through our analysis, we: (1) provide a structured understanding of some of the major issues causing failures, (2) identify and categorize factors/sources of failures into internal versus external driven, and (3) grounded in theory and supplemented by literature evidence, develop hypotheses and a corresponding conceptual model explaining the relationships among these factors/sources and the failure of foreign Internet firms. The proposed model serves as a means by which Information systems managers / Chief Information Officers (CIOs) / Technology and Business managers can understand the sources of failures and conduct an introspective exercise within the firm to plug some gaps before launching a business in a foreign country. Academically, the study has developed a theoretically-grounded comprehensive model to advance knowledge in a scantly researched area of challenges faced by the foreign Internet firms and to help in the development of strategies to mitigate these problems. The proposed model also adds to the current knowledge on information systems Socio-Technical Theory and the Comparative theory of Competitive Advantage.

Keywords: Foreign Internet Firms, Causes and Factors of failure, Patriotic tendencies, Perceived globalness, Sustainable business model, Network effect

\section{Introduction}

The last two decades have witnessed the rise of oriental giant 'China' in the Internet industry. China is now one of the largest Internet markets, with an Internet population of an estimated 772 million, 753 million mobile internet users and a promising future; the Internet penetration rate doubled from 2006's 25.5\% to 55.8\% by December 2017 (CNNIC, 2018; ChinaDaily, 2018).

This phenomenal growth, despite an increasing number of government regulations and a worldwide economic recession, could be partly attributed to favourable government policies on the sharing economy. The "Internet Plus" policy introduced in 2014 seemingly offers unprecedented opportunities to operate in the Chinese Internet market, albeit with some extended procedures at the local government level (Cheng \& Liu, 2016). 
Given these policies and the potential of profits and opportunities, foreign Internet firms have turned their focus on the Chinese market. Notably, two Internet giants from the United States, Uber and Airbnb, launched their businesses in China in 2014 and 2015 respectively. Yet two years later Uber China surrendered to its local rival Didi Chuxing. This has come at a cost, as Uber China is reported to have paid approximately $\$ 1$ billion per year in subsidies and captured less than 15\% of market share (Cheng \& Liu, 2016; Dou \& Chu, 2016).

Adding to this saga is the fact that Uber's failure in China is not the first time that a foreign Internet firm could not survive competition against a local rival. eBay, the first foreign Internet firm entering China in the $\mathrm{C} 2 \mathrm{C}$ segment, suffered a dramatic market share fall from $85 \%$ to $36 \%$ in 2005 as a result of Taobao's entry into the China market. Tencent QQ "monopolized Internet Message market" with a share of $84.4 \%$, effectively wiping out MSN who only managed a market share of $13.9 \%$ in 2006 . Google is another example with $16.6 \%$ market share compared to Baidu with 76.9\%; it had to leave China in 2010 due to regulatory issues (Oh \& Zhang, 2010).

In fact, nearly half (48\%) of foreign firms have failed and rolled back their Chinese operations within 2 years (China Bridge, 2013; Marquis \& Yang, 2014) of starting their business. Airbnb, the only surviving foreign Internet giant is also facing stiff competition from three Chinese competitors: Xiaozhu (Short rental), Tujia (Travel rental), and Ctrip (Integrated travelling services).

The problem is compounded by the fact that China is witnessing an explosive growth in online business activities with online retail transactions reaching an estimated RMB7.175 trillion in 2017, registering a year-on-year growth of 32.2 percent (CNNIC, 2018; Deloitte, 2016). While there seem to be many opportunities for Internet firms, it also raises questions about why some firms are failing in the Chinese market, despite efforts by Government to accentuate growth through favourable policies. The situation underlies a significant ongoing problem that merits investigation. Yet limited research exists on the reasons, challenges and issues contributing to the failure of foreign Internet firms in China. Motivated by this gap in knowledge, we study the following research question:

\section{What causes Internet firms to fail when they operate in a foreign country such as China?}

The main idea of this paper is to examine and identify some of the possible sources or factors driving failure of Internet firms in general, by learning from experience of China and build fundamental knowledge on the challenges of operating in a foreign Internet market. Drawing on the existing literature and using a theoretical foundation, we then develop a conceptual model to show relationships among the possible contributing factors and the outcome i.e, the failure of foreign Internet firms.

Through this study, we expect to facilitate the development of concrete strategies to avoid or handle this problem more effectively. The study contributes significantly in multiple ways:

1. It builds a structured understanding of issues and challenges faced by foreign Internet firms operating in China (Section 2);

2. It identifies a number of factors/sources of failures, categorizes them as internally or externally driven, and then builds some theoretical knowledge of them (Section 4);

3. Grounded in Theory and supplemented by literature evidence, it develops hypotheses explaining the relationships between the factors or sources and the failure of foreign 
Internet firms. This opens up opportunities for further modelling and examination of relevant issues (Section 4), and

4. It creates a conceptual model advancing a holistic understanding of the issues related to failure of foreign Internet firms, which adds to existing knowledge on information systems Socio-Technical Theory (STT) (Section 4).

\section{A critical perspective of relevant literature}

\subsection{Motivation for foreign Internet firms to operate in China}

Driven by profits and pursuing a globalization strategy, foreign Internet firms are actively extending their reach and penetration into overseas markets. For the purpose of this study, we adopt a definition of Internet firms from prior studies as "the firms that offer goods and services mainly using the Internet technology and infrastructure" (My, Kim \& Sayim, 2015).

Being the world's largest Internet market with 772 million users, 7.175 trillion CNY trading volume per year and a nearly $55.8 \%$ Internet penetration rate, China is naturally a hotbed of potential and opportunities in the Internet market (CNNIC, 2018). Adding to that, certain favourable government policies have enticed foreign firms to seek opportunities in the bullish Chinese Internet market.

However, despite all this optimism, the reality is far different. A number of foreign Internet firms such as eBay, MSN, Google and Uber have failed to capitalize on the potential and promise of the Chinese Internet market and have lost ground to their respective local competitors (also see Section 1). The only exception, so far, is Airbnb who entered into China in 2015 and despite many struggles has survived the challenges from its three local competitive "snipers" Xiaozhu, Tujia, and Ctrip (Carew, 2015; Han, 2015).

This situation paints a grim picture for foreign Internet firms and necessitates examination of the reasons, challenges, and issues that are causing failure. Based on a review of literature, the reasons for foreign Internet firms' failure in China can be broadly classified and considered from three perspectives: (1) cultural, linguistic and psychological differences (Section 2.2), (2) differing strategic approaches (Section 2.3), and (3) political, legal and social aspects (Section 2.4). We discuss these in detail comparing the differences in approaches taken by foreign Internet firms as against their local rivals.

\subsection{Reasons for failure: Cultural, linguistic, and psychological differences}

Cultural differences, as the most intuitive reason, have been identified by various researchers. Chinese users have significantly distinct expectations. Wang (2012) points to these differences and compared Asian against Western countries' cultures, i.e. "collectivistic" versus "individualistic" on the notion of "uncertainty avoidance" - i.e. the level of accepting uncertainty and ambiguity. They found that Chinese, as well as most Asians, are risk-averse and less trusting, and score significantly lower on these two criteria compared to westerners and even to the global average.

These cultural, linguistic and psychological tendencies translate into distinct preferences and perceptions requiring adjustments of business environments as well as product / service offerings. We discuss some of the issues identified in the literature below. 


\subsubsection{Ease of communication with the Sellers help generate trust}

Given the cultural context, secure online payment systems and communication with sellers are crucial to Chinese consumers' positive experience for doing online shopping. This can be seen from a comparison of Taobao and eBay payment systems.

Ou and Davison (2009) offer an example. Aliwangwang, a chatting application for buyers to contact with sellers is embedded in the Taobao (Chinese C2C portal) website. Compared to Skype or email used by eBay for communication between sellers and buyers, Aliwangwang is much more convenient, since users do not need to download and register to use this application and its associated features. Additionally, the application has an innovative feature that a blue or grey icon of Aliwangwang appears under every item selling at Taobao, indicating whether the seller is online and available to chat; this helps users in seeking more information and making wise buying decisions. With Chinese consumers having a "strong preference" to contact the seller, such functionality plays a critical role in the overall buying experience and completion of the sales process (Ou \& Davison, 2009).

Marquis and Yang (2014) suggest that not having an effective, easy-to-use communication tool is the key reason for eBay's failure. Although limited literature exists that has recognized cultural differences and preferences with an in-depth analysis (Ackerman \& Tellis, 2001), not much work has been done in an Internet business context. Similarly, some studies have analysed the impact of price or quality as the deterministic factors influencing Chinese buyers' purchasing decisions (Law, To \& Goh, 2008). Others have found an integrated website layout as one of the factors that drives users' acceptance and reduces the chance of failure (Zhou, Lu \& Wang, 2013). Overall, there is little knowledge about these issues in an Internet market context that includes foreign Internet firms as well. Hence, the need for more research in this context.

\subsubsection{Ease and modes of payments}

Alipay is the online payment system launched one year after Taobao was launched. Alipay used by Taobao users for shopping provides multiple methods of payments including online credit or debit card, cash on delivery, and allows adding funds to an online account at over 66,000 post offices or bank branches (Greeven, 2012). Compared to eBay this is much more flexible, as eBay only accepts online credit / debit card payments. Chinese prefer cash and bankbooks rather than cards, especially in the early 2000s when credit / debit cards were not generally accepted by many businesses. This difference is one of the possible causes of eBay's failure in China (Wang, 2012).

\subsubsection{Risk avoidance}

A customer's preference for avoiding risks when shopping online is facilitated by the seller's reputation. Ye et al., (2013) reported that there is a positive correlation between sales volume and customers' comments about a seller's reputation on Taobao. It supports the view that Chinese customers tend to choose a less risky commodity and care less about the price, whereas eBay's markets are price-based. This may explain why eBay is less popular in China compared to Taobao. However, since the research was conducted with data from Taobao China and eBay US, further research focused on the Chinese market will add value.

\subsubsection{Localization of shopping environment}

eBay, as the first C2C platform in China, applied an auction market model, which is "alien" to Chinese customers (China Bridge, 2013). In contrast, Taobao has a bargaining market model 
"designed by and for Chinese users" (Ou \& Davison, 2009), which allows customers to bargain with sellers, similar to a real-world business and which fits the habits of Chinese customers.

A similar problem exists in the way Uber operates, whose user interface was designed for American users and then copied into a Chinese version. Didi (Uber's local Chinese competitor) has a more localized interface. Specifically, customers have to send emails to Uber if they have any questions, while Didi has a button on main menu to call a customer service centre. Considering that email penetration rate in China is only $36.8 \%$ (CNNIC, 2016), this could be a hurdle to use of Uber's services. Chinese customers typically use a phone to hail a taxi online. It highlights that "a copy-and-paste" approach in China is not effective and does not contribute to success (Ke \& Sun, 2014).

\subsubsection{Perceived globalness}

Foreign firms also prefer a standardized service with global consistency. It leads to linguistic and cultural problems. Failing to localize with special features that cater to the different preferences of local customers do not help in engaging with them (Oliver, 2015).

However, Oh and Zhang (2010) provided contrasting evidence, suggesting that standardized user environment, which they call "perceived globalness" is an advantage. They argue that consumers may prefer the international brand as a symbol of social status. They conducted the research by "sociotechnical preference model", illustrating eight dimensions of the services provided by domestic and foreign firms, including "perceived globalness".

The linear regression results proved that "perceived globalness" is a significant factor that could influence consumers' choice. However, given that the questions asked in the questionnaire aimed to determine whether the interviewees agree with the concept of "perceived globalness" and not whether this concept has influenced their behaviour, the results should be treated with caution. While one can argue that such a perception, in particular for high-end goods exists, more work is needed to understand the influence of this concept on the choices made by consumers, and how significant this is.

\subsubsection{Patriotic tendencies}

When it comes to preference for foreign brands, another stream of thought suggests that some customers prefer domestic products for patriotic reasons (Oh \& Zhang, 2010). Terming it as "Consumer ethnocentrism" the researchers tested Chinese consumers' attitude towards domestic and foreign products. The results show a negative inclination towards buying products of foreign firms, though not significantly. Whilst various researchers (e.g., Dong \& Yun-tang, 2012) assert that it should be an important factor explaining why foreign corporations are failing in China, it is not limited to the Internet industry alone.

\subsection{Reasons for failure: Strategic and operational approaches}

A lack of understanding of customer preferences may also affect operating strategies and performance. When providing the same or similar types of services, firms in competition may distinguish themselves by adopting unique operating strategies (Ke \& Sun, 2014). We discuss some of these issues in the literature below.

\subsubsection{Sustainable Business model}

It is argued that a tailored long-term sustainable business model is crucial to success, whilst a "one size fits all" strategy leads to failure (China Bridge, 2013). 
The first major Sino-foreign Internet competition between Taobao and eBay points to the distinct business models they use. Taobao applied a "Fee-less business model" to attract both sellers and customers, whereas eBay copied its global strategy of generating profits by charging fees for providing a trading platform (Greeven, 2012).

It seems that Taobao's long-term strategic approach suited the local context better than eBay's well-established model based on its global marketing strategy. Additionally, the bargaining model used by Taobao versus the auction model of eBay seems to be one of the contributing factors leading to failure of eBay in China.

Providing free services to enlarge market share and then profiting from large sales volume is a business model that has been utilized successfully ever since Taobao drove eBay out of the Chinese market in 2006 (Jin, 2016).

Another example of sustainability of business model, similar to Taobao's, is Baidu's advertising business. Although repeatedly questioned and blamed on recent social media traffic for several advertisement-related incidents, Baidu is generating significant amount of income from its advertisement activities (CNNIC, 2016). Such a situation is contributed by Baidu's dominating market share as well as the loyalty from more than $60 \%$ of its customers, whose decisions are vastly influenced by Baidu's search results (Wang, 2012). In contrast, Google failed in China before it could find and launch a sustainable profit-generating model.

Airbnb, like its local rivals Tujia and Xiaozhu, has not been able to construct a sustainable model yet. Suggesting that "Growing our business is a higher priority now than profitability", the co-founder of Tujia acknowledged that Tujia has not yet reached a break-even point (Carew, 2015). Along with Tujia and Xiaozhu, Airbnb as a late-entrant into the market and is trying to expand by enlisting accommodations. Though it is difficult to get more accommodations listed, the growing number of orders and abundant cash flowing into the short-rental industry have shown promising prospects and a sign of maturity (Han, 2015). But one asks whether the existing model is feasible and sustainable. And what kind of business model is most suitable? Is the business model significant to Airbnb's future in China? Further analysis is required.

Uber and Didi applied and developed their business model further by offering subsidies. Founded in 2012, Didi initially focused on licensed taxi-hailing business, providing a free platform benefitting both taxi drivers and passengers. Having acquired $99 \%$ of taxi-hailing market shares, Didi started offering subsidies to both taxi drivers and passengers, after entry of other local rivals in the taxi business segment.

With the entry of Uber in Chinese market in 2014, Didi acquired or partnered with other local competitors to keep its hold on the market intact. Unlike Didi, Uber started its business with private cars, copying the US model. Didi on the other hand, continued broadening its business by developing a network of not only the licensed taxis but also enlisting private cars. The white-hot "subsidies war" became fiercer as both firms were striving for maximum market share. However, Uber was not able to sustain itself in the market for long and after spending more than $\$ 1$ billion per year to achieve less than 15\% market share, it declared its failure in China (Dou \& Chu, 2016).

Uber's business model could be considered as less effective and problematic; it was no surprise that it didn't work for Uber (Dou \& Chu, 2016). Ou and Davison (2009) suggest that the model based on offering subsidies is not a profit-oriented model. However, it has worked for Didi, 
as it is being used in a large number of cities in China, benefiting the public and drivers alike (Cheng \& Liu, 2016). It remains unclear, however, whether the failure of Uber is caused by its ineffective business model. There could be other elements of their operating strategy that may have caused Uber's failure, e.g., price differences as a result of use of different fee formula and subsidies, and differing consumer preferences, to name a few. Therefore, it will be worth examining other factors that may have had a role in Uber's failure in China.

\subsubsection{Operating strategies}

Researchers have also identified several specific differences among the operating strategy of various service providers (Dou \& Chu, 2016; Han 2015). First-mover advantage has been argued to be a possible factor. Dou and Chu, (2016) Han (2015), and Ou and Davison (2009) argued that a first-mover advantage is vital and played a role in the failure of Google, Uber, and Airbnb in China. Wang, (2012) however didn't find support for the first-mover advantage. For instance, eBay had the first-mover advantages as it started its operations in China before the birth of Taobao, yet eBay still could not survive against its local rival. Hence, eBay's failure is a stark reminder of how operating strategies of the service providers affect their chances in the market. Contrastingly as Uber and Airbnb are late entrants, hence their operating strategies warrant further examination.

\subsubsection{Network effect}

Greeven, (2012) introduced the concept of "Network effect," which essentially means an enterprise expanding its business into several interlinked complementary fields by forming a network of partners. For instance, Alibaba's network "ecosystem" consists of "centre" Taobao for shopping, Alipay for online payment, Alisoft for software service to sellers, and Alimama for posting specialized advertisements (Greeven, 2012).

Another example is Didi's "enterprise lines" which includes: taxi, private car, high class private car, ride-sharing, designated drivers, shuttle bus, test driving, and car rental (Cheng \& Liu, 2016). Baidu is following a similar trend and expanding its business to group purchase, take-out delivery and financial services, adding to its previous business including encyclopaedia, input tools, BBS, music, video, digital map and so on and so forth (Baidu, 2017). In contrast, foreign firms have failed to "weave" a similar network of partners. Nonetheless, there is no clear evidence indicating that the network effect is significant to users - or contributing to failure if not present.

To form a successful "network", choosing right local partners and investors with local information and staff is vital (Custer, 2015). For instance, Didi established a partnership with Tencent, whose products QQ and WeChat are the most popular instant messaging mobile applications in China (CNNIC, 2016; Dou \& Chu, 2016). In exchange for sharing Didi's profit; Tencent not only provides money but also big data analysis support, digital map services and WeChat advertising thus allowing WeChat users to push one button to use Didi's service without downloading and registering any specific app (Cheng \& Liu, 2016). As a rival to Didi, Uber made the accusation a number of times that their articles and messages were frequently blocked on WeChat (Dou \& Chu, 2016). It seems that partnership with domestic firms and investors is significant to a foreign firm's success.

\subsection{Political, legal, and social reasons}

Government regulations, political and legal aspects, also play a role in failure or success of a business in any country. Unlike in developed countries where markets are driven by the 
demand and supply equation, China's market economy system emphasizes the role of regulatory bodies in facilitating market operations, especially in case of direct foreign investment (Lee, 2010).

Several authors (Stevenson-Yang, 2007; Financial Times, 2005) have argued that local Internet firms are far better off in meeting the regulatory requirements, in comparison to foreign firms; this often leads to the foreign firms' failure. It is believed that tightening of regulatory policies contributed to the retreat of Google (Lee, 2010; Marquis \& Yang, 2014). Similarly, both Uber and Airbnb have had to deal with a range of regulatory requirements. Yet a clear policy on regulation concerning short-renting services is not yet available.

Stevenson-Yang, (2007) citing "2006 China Search Engine Survey Report” highlighted that based on Chinese users' views, Google's search results are more relevant than Baidu's. In addition, Wang (2012) points that Google uses fewer advertisements and offers unique services such as input tools, translators, notebook facilities and Google Mars. Yet Google was not able to operate successfully in China. However, the literature is split on the reasons for its failure. There has been a view that Google's servers in China were much slower and more liable to breakdown (Lee, 2010). Moreover, the market share of Google at $16.6 \%$ compares with Baidu's $76.9 \%$ in 2009 . The increasing gap between them points to other problems that Google may have had in the market (Oh \& Zhang, 2010). So it is possible that even if the regulatory matters had been resolved, Google may still not have been able to remain competitive due to its minority share in the market.

Interestingly, just like with Google, though the regulations applied to Uber and Didi equally, yet Uber was not able to survive. It is also noteworthy that Uber sold its China operation to Didi Chuxing on Aug 01, 2016, just a few days after an encouraging and soft policy was announced by the Government during last week of July 2016 (Abkowitz \& Carew, 2016; Cheng \& Liu, 2016).

Airbnb, along with local rivals Tujia, Xiaozhu, and Ctrip, are operating with an even more complicated business arrangement (Xinhua Insight, 2015). Short renting, as a new form of service in expanding sharing-services industry, is compliant with China's "Internet Plus" and sharing economy strategies, but government regulations need to evolve on that.

Examples from other countries show that, even in western countries Airbnb's business face several challenges on legal and market fronts (Somerville \& Bellon, 2016). However, this might be an advantage over local rivals since they have experiences negotiating with governments (Han, 2015). It could be that the success or failure of Airbnb may be decided by its relationships with the local governments. Custer, (2015) concludes that it is logical that foreign firms have to abide by China's government regulations, otherwise, there is only a "one-way ticket home."

\subsection{Summary of the literature review}

The above review suggests that failure of foreign Internet firms in China stems from multiple reasons including: cultural differences, linguistic disadvantages, dis-aligned business models, network impact, choice of local partner(s), and regulatory requirements, among others.

One aspect clearly arising from this discussion is the comparative advantage that local internet firms had over their foreign counterparts which has resulted in driving out the competition in the majority of the cases. It seems that local Internet firms leveraged their local knowledge, networks, capabilities and resources more competently to develop and deploy strategies to capture a greater market share, leading to failure of foreign Internet firms. 


\section{Theoretical Underpinning}

Drawing upon the review of the literature, we use the "Comparative Theory of Competitive Advantage" to build a conceptual model for reasons and challenges of entering Internet market in China and contextually similar countries / cultures.

The Comparative Theory of Competitive Advantage rejects the neo-classical assumption of the "theory of perfect competition" and posits that firms operate in a dynamic environment (Hunt \& Morgan, 1995). The key tenets of the theory are (Hunt \& Morgan, 1995):

1. Consumer demand is heterogeneous and dynamic with taste and preference of consumers changing;

2. Consumers have imperfect information about the products / services "that might match their tastes and preferences";

3. Humans, while serving dual role as consumers and managers of their firms, are constrained by self-interest. This points to the opportunistic nature of human beings and the fact that their morality, ethical behaviour, actions and deeds in life are subject to the significance of opportunity;

4. Fourth and fifth is that a firm strives to seek superior financial performance under the condition of imperfect information about customers and competitors. The use of notion of 'superior' instead of 'maximum' is "both because of the well-documented fact that they (the firms) lack the information to do so (i.e. they operate under bounded rationality [Simon 1979]), and because morality considerations at times constrain them (or some of them) from doing so."

The measure and relative importance of financial performance varies from firm to firm and industry to industry;

5. The sixth tenet is that the firms make use of available resources, both tangible and intangible, to produce efficiently and create offerings that are valuable to a segment of market or customer base;

6. Seventh, the resources available to a firm are "both significantly heterogeneous across firms and imperfectly mobile." The make-up and structure of resources available to a firm are unique and not "commonly, easily, or readily bought and sold in the marketplace."

Firms in competition can attempt to copy the resources of the successful competitors, but heterogeneity can still persist for a length of time. Firms with unique mix of resources - if able to use those resources in an effective way - can achieve a comparative advantage by developing offerings that are seen by the customers as value added and lower costs. The distinctiveness of offering is essentially dependent on the distinctiveness of inputs;

7. The theory also defines the role of management that is to "recognize and understand current strategies, create new strategies, select preferred strategies, implement or manage those selected, and modify them through time";

8. Ninth, in contrast to neoclassical theory which posits that the "structure of its (the firm's) industry, strictly determines its conduct (or strategy) and performance (profits)," the Comparative advantage theory suggests that the structure only influences that strategy and performance. The firms competing in a certain market need to develop their own 
strategy based on uniqueness of their resources and inputs thereby targeting specific set of customers, markets and competitors as deemed necessary.

\section{Development of a Conceptual model}

Drawing upon the critical review of the literature presented in Section 2, we identify a number of possible factors or sources contributing to failure of foreign Internet firms (Table 1). These factors are then used to drive hypotheses resulting in development of a conceptual model that shows the relationships between these factors and the outcome i.e. failure of Internet firms. The conceptual model is presented in Table 1.

\begin{tabular}{|l|l|l|l|}
\hline \multicolumn{1}{|c|}{ Factors } & $\begin{array}{c}\text { Internally vs } \\
\text { Externally } \\
\text { oriented }\end{array}$ & $\begin{array}{c}\text { Factor drawn } \\
\text { from } \\
\text { discussion in } \\
\text { Section(s) }\end{array}$ & \multicolumn{1}{|c|}{ Reference } \\
\hline 1. Strategic misalignment & Internal & 2.2 .2 & $\begin{array}{l}\text { Grewal, Chandrashekaran \& } \\
\text { Dwyer, (2008) }\end{array}$ \\
\hline 2. Lack of Internal preparedness & Internal & 2.2 .2 & Chen, (2013); Walcott, (2014) \\
\hline $\begin{array}{l}\text { 3. Lack of environmental } \\
\text { awareness }\end{array}$ & Internal & $2.2 .1,2.2 .2$, & Shkurti \& Leka, (2010) \\
\hline 4. Foreign organizational culture & Internal & 2.2 .3 & $\begin{array}{l}\text { Shin, (2004); Selmer \& de } \\
\text { Leon, (2002) }\end{array}$ \\
\hline 5. Foreign management style & Internal & 2.2 .2 & $\begin{array}{l}\text { Chen \& Myasin, (2008); } \\
\text { Wendt, (2015) }\end{array}$ \\
\hline $\begin{array}{l}\text { 6. Lack of business model } \\
\text { adjustment }\end{array}$ & Internal & 2.2 .2 & $\begin{array}{l}\text { Byhlin \& Holm, (2012); } \\
\text { Sleuwaegen, (2013) }\end{array}$ \\
\hline $\begin{array}{l}\text { 7. Lack of adjustment to } \\
\text { dynamics of business eco-system }\end{array}$ & Internal & $2.2 .2,2.2 .3$ & $\begin{array}{l}\text { Kwak, Lee \& Chung, (2012); } \\
\text { Rangan \& Drummond, } \\
\text { (2004) }\end{array}$ \\
\hline 8. Competitors' strategic leverage & External & $2.2 .1,2.2 .2$, & $\begin{array}{l}\text { Sofka \& Zimmermann, } \\
\text { (2005); Jurse \& Jager, (2014) }\end{array}$ \\
\hline 9. Regulatory constraints & External & 2.2 .3 & $\begin{array}{l}\text { Li, Yang \& Yue, (2007); } \\
\text { Sofka \& Zimmermann, } \\
\text { (2005) }\end{array}$ \\
\hline 10. Socio-cultural influences & External & 2.2 .3 & Hoffman \& Preble, (2004) \\
\hline 11. Language preferences & External & 2.2 .1 & $\begin{array}{l}\text { Piekkari, Vaara, Tienari \& } \\
\text { Säntti, (2005) }\end{array}$ \\
\hline 12. Patriotic tendencies & External & 2.2 .1 & Akin, (2016) \\
\hline
\end{tabular}

Table 1. Factors / sources of failure of foreign Internet firms

\subsection{Internally driven Sources}

\subsubsection{Strategic misalignment}

Strategic alignment is defined here as "the alignment of organizational strategies to the needs and context of the business eco-system in which the organization operates."

Drawing upon the tenets of the Comparative Theory of Competitive Advantage, a firm must use its resources in such a way that these resources create value for the targeted set of customers. Organizations do not have unlimited resources at their disposal and their use of resources is often a strategic decision. Therefore, if the use of organizational resources is strategically 
misaligned, the resources could be mis-utilized and do not end up creating value for the target set of customers (Grewal, Chandrashekaran \& Dwyer, 2008).

Strategic misalignment has remained one of the issues when multinational companies establish strategies for their foreign subsidiaries in line with their global strategies which may not fit to the local context (Grewal, Chandrashekaran \& Dwyer, 2008).

Strategic alignments therefore, requires that foreign Internet firms establish long term goals as well as the corresponding strategies and tactics that suit the local context. These include setting up an organizational structure that has an understanding of: local business environment, cultural norms, people's mindsets, regulatory environment; and has a leadership team made up of people that are locally connected or born, with an office infrastructure that can help facilitate operations effectively. Also needed are a good branding strategy, appropriate marketing and sales strategy (pricing, promotion etc.), understanding of local distribution channels, financial markets, customer buying capacities, and local market trends (Greeven, 2012).

However, a number of foreign firms have failed to strategically align their business operations to the Chinese context and were not able to capitalize on the available market opportunities and operate sustainably (Marquis \& Yang, 2014). Given the above, we propose:

H1: A strategic misalignment to the needs of local market is significantly associated with the failure of foreign Internet firms.

\subsubsection{Lack of internal preparedness}

An internal preparedness to enter into a foreign market is defined here as "the state of being prepared with resources, information, appropriate network of contacts, and human resource capabilities to start, operate and sustain a successful business operation."

An internally well prepared foreign firm will do an internal assessment of whether their human resources are capable to start, operate, and sustain a business on a foreign land, both remotely and on ground. The firm will also look at the internal processes and see if they are tailorable and scalable to the needs and context of foreign operations. Having an assessment of the financial and physical resources needed and availability and appropriateness of the resources to the local context is a key indicator of internal preparedness.

According to the tenets of the Comparative Theory of Competitive Advantage, firms must identify a set of unique resources to be sustainable in the market. The internal prepared assessment, therefore, will help firms understand whether they have the right balance of resources to compete and sustain in a foreign market. The evidence shows that Uber and eBay were not well prepared when they entered Chinese market, as their processes and business operations were not entirely compatible to local customer preferences and hence these foreign firms faced challenges and subsequently failed (Ke \& Sun, 2014).

Drawing upon the above discussion, we propose the following hypothesis:

H2: A lack of internal preparedness for entering and operating into a foreign Internet market is significantly associated with the failure of foreign Internet firms.

\subsubsection{Lack of environmental awareness}

The understanding of the local market eco-system, including customers, suppliers, distribution channels, regulations, tax regime, culture, values, resources availability, access to 
utilities and infrastructure (and the service providers thereof) and financial and banking channels is expected to facilitate starting and continuing operations in China. A lack of environmental awareness has caused failure of foreign firms such as eBay when they used their 'auction model' in China leading to their failure (China Bridge, 2013).

The above argument also corresponds to information systems Socio-Technical Theory (STT) which emphasizes the fit between technical and social context (Bostrom \& Heinen, 1977).

If the firm lacks an awareness of its eco-system, it will not be able to seek and deploy the resources that facilitate its sustainable operations. This is consistent with the tenets of the Comparative Theory of Competitive Advantage, which calls for firms to know and use their resources in a way that create a unique mix of the resources. We therefore propose:

H3: A lack of environmental awareness for entering and operating into a foreign Internet market is significantly associated with the failure of foreign Internet firms.

\subsubsection{Foreign organizational culture}

The culture of an organization has significant bearing on the strategic and operational functioning of an organization (Degravel, Wilkin \& Zhou, 2016). Organization culture not only affects the processes, policies, and ways of working but also influences the norms and behaviours of people working in the organization. Therefore, imposing a foreign culture that is not aligned or compatible to a particular context can cause challenges and affect the operations of a firm (Shin, 2004).

Organization culture is also considered a resource because of its impact on the sustainability of an organization. Therefore, when firms start their operations in a foreign country, they often impose the parent organization culture - which is counterproductive as we discussed in the context of Chinese experience of foreign firms.

Drawing upon the tenets of the Comparative Theory of Competitive Advantage which advocates the wise use of resources to create a comparative advantage, we believe that imposing a foreign organizational culture may create distortion in the development of unique assets. Thus, we propose:

H4: A foreign organizational culture is significantly associated with the failure of foreign Internet firms.

\subsubsection{Foreign management style}

Management style is potentially one of the most influential drivers of motivation, inspiration and productivity within an organization (Femi, 2015). Management style is generally contextual and needs to be tailored to environment to achieve the results. Dealing with human beings is a dynamic process and imposing a management style that does not fit the norms, behaviours and cultural context can lead to failure (Chen \& Myasin, 2008).

The failure of foreign internet firms operating in China might be attributable to their management style, as it did not take into account the local conditions properly. The failure of eBay and Uber are stark examples (Section 2).

According to the Comparative Theory of Competitive Advantage, firms choose a management style and strategies that give them comparative advantage. These firms modify their strategies as needed to achieve the advantage. From the discussion in Section 2, we can argue that foreign internet firms in China were not able to modify their management style effectively, and this contributed to the challenges they faced. 
Therefore, drawing from the theory and given the above discussion, we hypothesize:

H5: A foreign management style is significantly associated with the failure of foreign Internet firms.

\subsubsection{Lack of business model adjustment}

We define business model adjustment as the "ability of firms to fine-tune or modify their business model to operational needs of the changed context."

Firms operating in foreign countries, therefore, would need to understand the types of business model that suits the needs of operating in that country (Byhlin \& Holm, 2012; Sleuwaegen, 2013). A lack of business model adjustment has led foreign Internet firms in China to face various challenges as discussed in Section 2.

The notion of business model adjustment also confirms to the tenets of the Comparative Theory of Competitive Advantage, which states that a firm's structure must not be an impediment to its strategies. Hence firms wanting to achieve advantage over competitors need to adjust their structure, in this case adjustment of business model, to be able to execute strategy that suits the market and the needs of target customers. Following the above discussion, we propose:

H6: A lack of business model adjustment to the local needs is significantly associated with the failure of foreign Internet firms.

\subsubsection{Lack of adjustment to dynamics of business eco-system}

We define adjustments to dynamics of business eco-system as "the ability of an organization's structure, systems and processes to respond flexibly and adjust to the needs of changing business eco-system."

To be able to adjust to the dynamics of business eco-system, a firm needs to establish a scalable and flexible organizational structure, systems and processes that can be refined, modified and adjusted as needed in wake of changing dynamics of the business ecosystem (Kwak, Lee \& Chung, 2012). Building managerial and organization-wide human resource capabilities is critical in implementing the actual adjustments (Kwak, Lee \& Chung, 2012; Rangan \& Drummond, 2004). The failure of foreign internet firms such as Uber, eBay could be attributed to their inability to adjust to the dynamics of business eco-system after launching their operations in China (Section 2).

The adjustment to the dynamics of business eco-system also confirms to the tenets of the Comparative Theory of Competitive Advantage, which proposes that managers should adjust the strategies through time. Adjustment to dynamics of business eco-system could mean focusing both inwardly and outwardly. These adjustments could be repositioning of products and services, re-branding, adjusting marketing and sales strategies, building new enhancements in products and services, adjusting organizational culture, and restructuring of internal hierarchical and staff structures, to name a few. Drawing upon the above discussion, we hypothesize:

H7: A lack of adjustment to dynamics of business eco-system is significantly associated with the failure of foreign Internet firms. 


\subsection{Externally imposed Sources}

\subsubsection{Competitors' strategic leverage}

We define competitors' strategic leverage as "the ability of competitors to strategically manoeuvre their position and available resources to achieve maximum advantage in the market."

Competitors with local knowledge of markets, customers, cultural and business norms will be expected to have the ability to strategically manoeuvre their position (Jurse \& Jager, 2014). Firms starting a business in a foreign market may, therefore, face challenges from their local competitors. Because local firms are expected to have better market intelligence and understanding; they will be better embedded in the local population, have stronger networks with suppliers and distributors, and know the psyche of customers better. Such a position will help local firms competing against foreign counterparts to deal with market dynamics and uncertainties effectively and proactively (Sofka \& Zimmermann, 2005).

The literature evidence shows that one of the reasons foreign internet firms in China faced challenges and were not able to operate sustainably was because their local competitors outmanoeuvred them by offering products, services and strategizing in a way that better fits the needs of Chinese customers (Section 2).

The position is consistent with the tenets of the Comparative Theory of Competitive Advantage which proposes that under the conditions of imperfect information about customers and competitors, the firms that use their situation better achieves superior outcomes. Thus, we propose:

H8: Competitors' strategic leverage is significantly associated with the failure of foreign Internet firms.

\subsubsection{Regulatory constraints}

Regulatory constraints have been identified in the literature as one of the key reasons for failure of foreign internet firms in China (Section 2). These constraints include policies, procedural complications and legal disposition which could be very different from those applied in the foreign firms' world headquarters (Li, Yang \& Yue, 2007; Sofka \& Zimmermann, 2005). Interpretation of policies and laws could also be an impediment in terms of understanding and implementing the policies according to the local requirements (Li, Yang \& Yue, 2007).

This situation gives a comparative advantage to the local firms as they will be better positioned to understand, implement and comply with the policies and traverse through the legal landscape (Section 2; Li, Yang \& Yue, 2007; Sofka \& Zimmermann, 2005).

This is also consistent with the argument put forward by the Comparative Theory of Competitive Advantage. Therefore, we test the following hypothesis.

H9: Regulatory constraints imposed by the host country are significantly associated with the failure of foreign Internet firms.

\subsubsection{Socio-cultural influences}

We define socio-cultural influences as "the social and cultural parameters ingrained in a society's ways and means of dealing with day-to-day life and needs that are often not codified or explicitly expressed." 
Socio-cultural influences are often dynamic in nature and depend on human interactions. There is always a level of unpredictability which makes it challenging to codify these influences and develop concrete strategies (Hoffman \& Preble, 2004). However, it is expected that the local rivals of foreign firms will have a distinct advantage in understanding and responding to effects of socio-cultural influences. The literature evidence shows that Uber, eBay and other foreign Internet firms in China faced great challenges in dealing with the sociocultural tendencies (Section 2).

Consistent with the Comparative Theory of Competitive Advantage argument that seeks firms to establish strategies that are compatible for target customers and markets, we hypothesize:

H10: Socio-cultural influences are significantly associated with the failure of foreign Internet firms.

\subsubsection{Language preferences}

Language preferences have been found to be one of the common challenges for firms when they operate in a foreign market (Piekkari, Vaara, Tienari \& Säntti, 2005). The literature shows that foreign Internet firms faced considerable challenges due to language preferences of Chinese consumers (Section 2). While having website and local staff can help in reducing the barriers, it is also important that product information, support and after-sales services and managerial staff should be localized to reduce possibilities of failure.

Having local language compatibilities across various spheres of operation will help in building the required rapport and impetus for sustainable operations. Such a proposition is also consistent with the tenants of the Comparative Theory of Competitive Advantage. We therefore hypothesize as follows:

H11: Language preferences of customers are significantly associated with the failure of foreign Internet firms.

\subsubsection{Patriotic tendencies}

We define patriotic tendencies as "the preference of customers to buy and use locally made products and services as a matter of allegiance and respect to the country and nation."

Patriotic tendencies have been found to be one of the factors that contributed to challenges faced by the foreign internet firms in China (Section 2). Firms operating in foreign market need to be aware of possibilities of such tendencies and should design measures and strategies to reduce the impact of such tendencies (Akin, 2016).

Developing tailored strategies to mitigate or lessen the impacts of patriotic tendencies is in line with the tenets of the Comparative Theory of Competitive Advantage as well which underscores the need for tailored strategies keeping in view the target customers. We, therefore, hypothesize:

H12: Patriotic tendencies of customers are significantly associated with the failure of foreign Internet firms. 
Internally driven sources of failure

- Strategic misalignment

- Lack of internal preparedness

- Lack of environmental awareness

- Foreign organisational culture

- Foreign management style

- Lack of business model adjustment

- Lack of adjustment to dynamics of business eco-system

Externally driven sources of failure

- Competitors' strategic leverage

- Regulatory constraints

- Socio-cultural influences

- Language preferences

- Patriotic tendencies

Failure of Foreign Internet Firms

Figure 1. The Conceptual Model

\section{Discussion and Conclusion}

A number of foreign Internet firms operating in China have failed to sustain their position in the market and have lost out to their local rivals. The list includes big names such as eBay, Google and more recent cases like Uber and Airbnb. The cost of failure runs in millions of dollars and stakes have been high. This has raised questions about what is causing such failures.

Compounding the problem is a lack of studies that have investigated the sources and issues driving these failures. With the exception of a few studies (e.g., Cheng \& Liu, 2016; Dou \& $\mathrm{Chu}$, 2016), a comprehensive understanding is still lacking.

Motivated by this gap in knowledge, the study described in this paper lays the foundation for a systematic understanding of sources of failure of foreign Internet firms in China by developing a theory-driven conceptual model. In doing so, we have identified a number of possible factors or sources of failure, and have framed them in the model to advance our understanding of relationships among these factors and the outcomes.

We build upon the existing knowledge and literature evidence and propose that these factors are both internally and externally oriented. The internally driven factors comprise both strategic and operational types. Some of possible strategic sources of failure are strategic misalignment, and lack of business model adjustments. Internally driven operational sources of failure are lack of internal preparedness, lack of environmental awareness, and lack of adjustment to dynamics of eco-system.

The extent to which some of these factors cause failure could be understood by testing the hypothetical relationships as shown in the conceptual model. We also posit that model should 
take into account the moderating effects of the size of firms, the number of foreign staff, and the location of foreign firm's world headquarters as well as their location in China, to build a more comprehensive understanding of the reasons for failure of foreign Internet firms in China.

\section{Implications, Future directions and Limitations}

\subsection{Implications for theory and practice}

The study makes several significant contributions and has implications for theory and practice. Academically, the study has developed a theory-driven comprehensive conceptual model for advancing understanding of factors and sources of failures and the possible interrelationships. Secondly, by classifying the factors and sources into internally and externally oriented sources, the model proposed by this study is a significant advancement towards looking at the issue of foreign Internet firms' failure more comprehensively. Thirdly, the factors identified cover a broad range including strategic, operational, socio-cultural, and human preference issues to build an in-depth knowledge. Finally, the conceptual model extends earlier work on information systems Socio-Technical theory (STT) which emphasizes a correspondence and fit between technology and social context for achieving the best outcome and avoiding failures of technology driven business ventures such as those examined by this study. Such an understanding is also in line with the study published in MIS Quarterly by Bostrom and Heinen, (1977).

Managerially, the model is a good starting point for firms to understand what might be causing the failure of foreign Internet firms in China. The model could serve as an introspective device for managers to plug some gaps before launching a business in a foreign country. The model can also serve as a foundation for managers through which to devise appropriate strategies by learning from the experience of others as has been discussed in this study.

\subsection{Future research work}

The study has opened up a number of opportunities for further research. Firstly, the model can be extended by inclusion of more factors and sources of failure to build a comprehensive understanding of the issues. Secondly, while a number of internal and external factors could be causing the failure, the role of leadership and management is critical in all cases. Therefore, further in-depth studies are required to investigate whether leadership and management is the trigger behind other sources of failure. Thirdly, more work is needed to identify moderating and mediating factors such as: organizational size, location of headquarters, location in China or a foreign country of operation, management configuration, size of foreign staff, and investments in dollars, that may have a role in influencing the relationships between factors and the outcomes. Finally, developing a model that is well-grounded in theory provides an opportunity for future work of undertaking either a mixed-method or a purely quantitative study to test the proposed hypotheses and extend knowledge on information systems Socio-Technical Theory and the Comparative Theory of Competitive Advantage.

\subsection{Limitations}

The study has some limitations. While efforts were made to take into account as many factors as possible to build a conceptual model explaining the relationships among these factors and the failure of foreign Internet firms, the model does not present an exhaustible list of factors 
and the corresponding relationships. Another limitation of the study comes from the lack of depth of academic literature on the subject, which could hinder creation of a more comprehensive model of factors driving the failure of foreign Internet firms. Also due to the fast-paced developments of Internet in China, the consumer behaviors and habits are changing frequently which could also require changes to the configuration of relationships and updating of the model. Finally, while this study has significantly advanced theoretical knowledge by developing a comprehensive model, however, it remains to be tested in the field.

\section{Acknowledgements}

The authors would like to thank the editor and the anonymous reviewer for their constructive comments and insightful suggestions on an earlier version of the paper, and Roger Tagg for his proof editing of the article.

\section{References}

Akin, M. (2016). 'The Relationship between Ethnocentric Tendencies of Turkish Consumers and Socio-Psychological Factors', Int. Review of Management and Business Research, 5(4), 1394.

Ackerman, D., \& Tellis, G. (2001). ‘Can culture affect prices? A cross-cultural study of shopping and retail prices', Journal of Retailing, 77(1), 57-82.

Abkowitz, A. \& Carew, R. (2016). 'Uber Sells China Operations to Didi Chuxing', Wall Street Journal, https://www.wsj.com/articles/china-s-didi-chuxing-to-acquire-rival-uber-schinese-operations-1470024403 (Viewed: 31-01-2018)

Baidu (2017). 'Baidu Milestones and Investor Relations' http://ir.baidu.com/phoenix.zhtml?c=188488\&p=irol-milestones (Viewed: 31-01-2018)

Bostrom, R.P., \& Heinen, J.S. (1977). 'MIS problems and failures: a socio-technical perspective, part II: the application of socio-technical theory'. MIS quarterly, 11-28.

Byhlin, H., \& Holm, E. (2012). 'Entering the Chinese e-merging market: A single case study of business model adjustment', Thesis: Umeå School of Business and Economics.

Carew, R. (2015). 'Investors Flock to Chinese Travel Site', Wall Street Journal - Eastern Edition, 266(28), C1-C3.

Chen, W. (2013). 'Get your feet wet-a study of entry strategy of Dutch architecture firms in China', Thesis submitted to Technical University of Delft

Chen, W., \& Myasin, M. (2008). 'Working with Chinese culture in luxury hotels in Shanghai: an expatriate manager's perspective on management challenges', International Journal of Chinese Culture and Management, 1(2), 199-218.

Cheng, W. \& Liu Q. (2016). 'DiDi (Sharing Economy Changes China) (Chinese Edition)', Posts \& Telecom Press, ISBN: 978-7-115-42503-4.

China Bridge. (2013). 'Foreign Giants failing to strike Gold in China', China Bridge, http://cbichinabridge.com/foreign-giants-failing-strike-gold-china (Viewed: 31-01-2018) 
ChinaDaily (2018). 'Nearly 69\% of Chinese netizens use online payment: report,' http://www.chinadaily.com.cn/a/201801/31/WS5a71aeaaa3106e7dcc13a038.html (Viewed: 17-02-2018)

CNNIC (2016). '38th Statistical Report on Internet Development in China', https://cnnic.com.cn/IDR/ReportDownloads/201611/P020161114573409551742.pdf

CNNIC (2018). '41st Statistical Report on Internet Development in China', http://www.cnnic.net.cn/hlwfzyj/hlwxzbg/hlwtjbg/201801/P020180131509544165973.pd f (Viewed: 17-02-2018)

Custer, C. (2015). 'The 3 biggest reasons foreign companies fail in China', TechInAsia. https://www.techinasia.com/3-biggest-reasons-foreign-companies-fail-china

Degravel, D., Wilkin, C.L., \& Zhou, X. (2016). 'The fluid paradigm': the impact of national culture on small business management', Journal for International Business and Entrepreneurship Development, 9(1), 62-87.

Dong, L., \& Yun-tang, Z. (2012). 'Recessive, dominant and direct situation of home products consciousness - Based on the theory of social approval' In Management Science and Engineering (ICMSE), 2012 International Conference on (pp. 739-744). IEEE.

Dou, E. \& Chu, K. (2016). ‘Uber's Efforts to Build Chinese Business Ultimately Fail Against Homegrown Rival', Wall Street Journal, https://www.wsj.com/articles/ubers-efforts-tobuild-chinese-business-ultimately-fail-against-homegrown-rival-1470056431

Femi, A.F. (2015). 'Influence of Management Style on Workers' Productivity in Nigeria' Machine Tools, Osogbo, Osun State, Nigeria. International Journal of Innovative Research and Development, ISSN 2278-0211, 4(4).

Grewal, R., Chandrashekaran, M., \& Dwyer, F. R. (2008). ‘Navigating local environments with global strategies: A contingency model of multinational subsidiary performance', Marketing Science, 27(5), 886-902.

Greeven, M. (2012). 'The case study: How Taobao bested eBay in China', The Financial Times, March 13, 2012, 10.

Han, Y. (2015). 'Three challenges facing Airbnb in China', Business Insider, http://www.businessinsider.com/three-challenges-facing-airbnb-in-china-2015-8

Hoffman, R.C., \& Preble, J.F. (2004). 'Global franchising: Current status and future challenges', Journal of Services Marketing, 18(2), 101-113.

Hunt, S.D., \& Morgan, RM. (1995). 'The comparative advantage theory of competition', The Journal of Marketing, 1-15.

Jin, C. (2016) 'Bao Pin Zhan Lue', Beijing: Beijing United Publishing Co., Ltd.

Jurse, M., \& Jager, J. (2014). 'Complexities of the firm marketing channel strategy management in international markets', In An Enterprise Odyssey. International Conference Proceedings (p. 1208). University of Zagreb, Faculty of Economics and Business

Ke, X. \& Sun, Q. (2014). 'Study of CSF in China's B2C E-Commerce Based on Expert Evaluation', Journal of Electronic Commerce in Organizations, 12(2), 31-45. 
Kwak, J., Lee, H., \& Chung, D.B. (2012). 'The evolution of alliance structure in China's mobile telecommunication industry and implications for international standardization', Telecommunications Policy, 36(10), 966-976.

Law, R., To, T., \& Goh, C. (2008). 'How do Mainland Chinese travelers choose restaurants in Hong Kong?: An exploratory study of individual visit scheme travelers and packaged travelers', International Journal of Hospitality Management, 27(3), 346-354.

Lee, M. (2010). 'Revisiting the 'Google in China' question from a political economic perspective', China Media Research, 6(2), 15-24.

Li, J., Yang, J.Y., \& Yue, D.R. (2007). 'Identity, community, and audience: How wholly owned foreign subsidiaries gain legitimacy in China', Academy of Management Journal, 50(1), 175190.

Marquis, C. \& Yang, Z. (2014). 'Learning the Hard Way: Why Foreign Companies That Fail in China Haven't Really Failed', China Policy Review, 10, 80-81. https:/ecommons.cornell.edu/bitstream/handle/1813/40209/Failures_CPR.pdf;sequence $=4$

My, N.N.Q., Kim, P.S., \& Sayim, M. (2015). 'Initial performance of IPOs and the bankruptcy risk: A comparison of internet firms and the traditional firms', Research in Business and Management, 2(2), 34-51

Oh, L. \& Zhang, Y. (2010). 'Understanding Chinese Users' Preference for Domestic over Foreign Internet Services', Journal of International Consumer Marketing, 22(3), 227-243.

Oliver. (2015). 'Why do International Companies Fail in China?', http://marketingtochina.com/why-do-international-companies-fail-in-china

Ou, C.X. \& Davison, R.M. (2009) ‘Why eBay Lost to TaoBao in China: The Global Advantage', Communications of the ACM, 52(1), 145-148.

Piekkari, R., Vaara, E., Tienari, J., \& Säntti, R. (2005). ‘Integration or disintegration? Human resource implications of a common corporate language decision in a cross-border merger', The International Journal of Human Resource Management, 16(3), 330-344.

Rangan, S., \& Drummond, A. (2004). Explaining outcomes in competition among foreign multinationals in a focal host market. Strategic Management Journal, 25(3), 285-293.

Selmer, J., \& de Leon, C.T. (2002). 'Parent cultural control of foreign subsidiaries through organizational acculturation: a longitudinal study', International Journal of Human Resource Management, 13(8), 1147-1165.

Shin, M. (2004). 'Convergence and divergence of work values among Chinese, Indonesian, and Korean employees', In Management and International Review (pp. 105-129).

Shkurti, R., \& Leka, B. (2010). 'Development of the Accounting Profession in Albania in the new era of market economy', Studies in Business \& Economics, 5(3).

Sleuwaegen, L. (2013). 'Scanning for profitable (international) growth', Journal of Strategy and Management, 6(1), 96-110.

Sofka, W., \& Zimmermann, J. (2005). 'There's no Place Like Home: A Strategic Framework to Overcome Liability of Foreignness in the German Car Market', ZEW Discussion Papers, 05-84 
Somerville, H. \& Bellon, T. (2016). 'Airbnb's Legal Challenges Get Real', Time.com, http://time.com/money/4541529/airbnb-legal-challenges/ (Viewed: 31-01-2018)

Stevenson-Yang, A. (2007). 'The Curse of the Chinese Internet', Far Eastern Economic Review, 170(3), 41-44.

Walcott, S. (2014). 'Capitalist China comes to the Southeastern United States: localizing foreign direct investment in the Carolinas and Georgia', Southeastern geographer, 54(3), 291-307.

Wang, X. (2012). 'Foreign direct investment and innovation in China's e-commerce sector', Journal of Asian Economics, 23(3), 288-301.

Wendt, K. (2015). How does political, economic and social transformation in China challenge the market for MNCS, and to what extent does this affect the strategic focus of MNCS. Master's Thesis Copenhagen Business School.

Xinhua Insight (2015). 'Xinhua Insight: Sharing economy shaking up business in China', http://news.xinhuanet.com/english/2015-08/25/c_134554335.htm (Viewed: 31-01-2018)

Ye, Q., Xu, M., Kiang, M., Wu, W., Sun, F. (2013) 'In-Depth Analysis of the Seller Reputation and Price Premium Relationship: A comparison between eBay US and Taobao China', Journal of Electronic Commerce Research, 14(1), 1-10.

Zhou, T., Lu, Y., \& Wang, B. (2013). 'A comparative analysis of Chinese consumers' increased vs. decreased online purchases', In E-Commerce for Organizational Development and Competitive Advantage (pp. 40-57). IGI Global.

Copyright: (C 2018 Ram \& Zhang. This is an open-access article distributed under the terms of the Creative Commons Attribution-NonCommercial 3.0 Australia License, which permits noncommercial use, distribution, and reproduction in any medium, provided the original author and AJIS are credited.

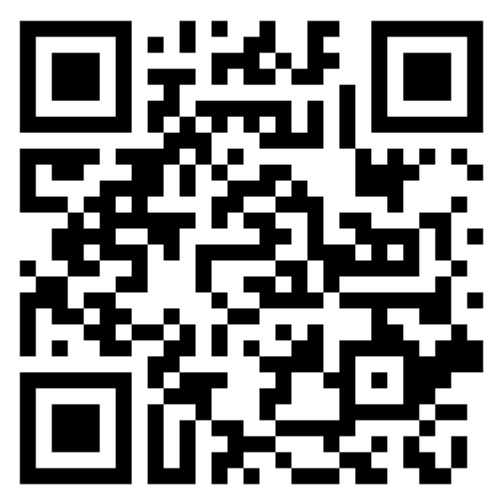

